\title{
Storage and germination treatments for seeds of an ornamentally important palm, Livistona rotundifolia (Lam.) Mart.
}

\author{
B.L.G. Sanjeewani ${ }^{1}$, K.M.G.G. Jayasuriya ${ }^{1,2^{*}}$, M. Thilina R. Fernando ${ }^{1}$ and J.W. Damunupola ${ }^{1,2}$ \\ ${ }^{I}$ Department of Botany, Faculty of Science, University of Peradeniya, Peradeniya. \\ ${ }^{2}$ Postgraduate Institute of Science, University of Peradeniya, Peradeniya.
}

\begin{abstract}
Livistona rotundifolia (Lam.) Mart. is an ornamentally important plant in Sri Lanka with a high demand for both cut foliage and pot plant production for the foreign market. Propagation through seeds, poor germination and the storage of seeds are the main constraints in L. rotundifolia cultivation. During the current study, seed germination and storage behaviour of L rotundifolia have been investigated to identify the causes for its poor germination and poor storability. The moisture content of seeds was determined using the oven-dry method. Germination of the seeds was studied under light/dark and dark conditions and the embryo : seed ratio was determined in fresh seeds and in seeds soon after the radicle emergence. The effect of storage at eight different storage conditions was evaluated. The seeds had a moisture content of $36.8 \%$ suggesting that they are recalcitrant. Recalcitrancy of seeds is further supported where none of the seeds germinated when they were stored at $-2{ }^{\circ} \mathrm{C}$. Freshly collected seeds germinated only in dark conditions (58\%). Even in dark conditions, the seeds took 2 months to complete germination. Although seeds had a low embryo : seed ratio, it remained unchanged during germination. Thus, the dormancy of seeds can be categorized as the non-deep physiological dormancy. This is the first record of a species producing seeds with no morphological dormancy in Arecaceae. The seeds stored in polythene bags with coir dust at $4-8{ }^{\circ} \mathrm{C}$ showed the highest survival (97\%) and thus, this treatment can be recommended to store $L$. rotundifolia seeds for a minimum of 5 months.
\end{abstract}

Keywords: Dark requirement, Livistona rotundifolia, non-deep physiological dormancy, recalcitrance.

\section{INTRODUCTION}

Livistona rotundifolia (Lam.) Mart. plays a major role in the ornamental plant industry in Sri Lanka. It is an ornamentally important plant with a high demand for both cut foliage and pot plant production in local as well as foreign markets (Svinningen et al., 2010). It is one of the common palms grown in net houses of horticulture industries in Sri Lanka (Jegathambigai et al., 2008). Propagated through seeds, poor germination and storability of seeds are the main constraints in L. rotundifolia cultivation (personal communication). Only a few seeds germinate in germination orchards and the seeds can only be stored for $<1$ month. When large orders of L. rotundifolia seedlings are required, the growers have to totally depend on fresh seed collections (personal communication). Furthermore, the lack of published data on germination and storability of L. rotundifolia directed the present study to investigate the basic characteristics of seed germination and storability of seeds.

Although, information on germination and storage of $L$. rotundifolia seeds is lacking, some information is available on germination and storage of other Livistona species. Wen and Song (2007) and Wen (2009) have shown that during the development of Livistona chinensis seeds, they become cryotolerant and lose the cryotolerance ability with maturation. Mature L chinensis seeds cannot survive at sub zero temperatures even for one week. However, the excised embryos can be stored in liquid nitrogen after drying up to $20 \%$ seed moisture content (Wen, 2009). According to the results of Peng et al. (2011), L. chinensis seeds lose viability when dried up to $8 \%$ moisture content and thus, the authors categorized L. chinensis seeds as recalcitrant seeds. In contrast, results of Ehara et al. (2002) showed that L. chinensis seeds germinated even after they were soaked in sea water 
for 60 days. Ellis et al. (2007) have reported that seeds of $L$. cochinensis have an orthodox storage behaviour. L. chinensis seeds germinate without any treatment; however they take 50-60 days from sowing to complete germination (Singh et al., 2010). Thus, the seeds may have a slight physiological dormancy or morphological dormancy similar to most of the other Arecaceae species (Baskin \& Baskin, 1998). Similarly, Lack (2009) reported that seeds of $L$. rigida do not require any pre treatment for germination however, it took more than 1 month to sprout.

\section{METHODS AND MATERIALS}

\section{Studied species}

Livistona rotundifolia is a hermaphroditic palm tree, which can reach a height of $45 \mathrm{~m}$. This plant is native to Malaysia, Indonesia and the Philippines. In its native habitat, this species occur in swamp forests, seasonally dry swamp forests, mangrove margins, rainforests, moist evergreen forests and in river banks (Dowe, 2009). However, it has been introduced to many tropical and subtropical countries as an ornamental species (De Zoysa, 2000).

\section{Seed collection}

Mature fruits were collected from $L$. rotundifolia trees in Ambalangoda $\left(80.05^{\circ}, 6.23^{\circ}\right)$, Sri Lanka. The fruits were stored in polythene bags and brought to the labratory. Seeds were extracted from healthy fruits and the experiments were initiated within 2 wks from collection.

\section{Seed moisture content}

Fifteen seeds, which were initially weighed (with a digital chemical balance) were oven dried at $120{ }^{\circ} \mathrm{C}$ for $3 \mathrm{hrs}$ (ISTA, 2008). Retrieved seeds were reweighed individually and then the seed moisture content (MC) was determined on fresh mass basis.

\section{Effect of drying on seed viability}

Two samples of 3 replicates with 15 seeds each, were weighed initially. Seeds were air dried to $20 \%$ or $10 \%$ seed MC, assuming that their initial seed MC was $36.8 \%$ (MC determined by the first experiment). When seed samples reached the desired MC (20\% or $10 \%)$, they were incubated on moistened filter papers in petri plates under laboratory temperature conditions $\left(26 \pm 2{ }^{\circ} \mathrm{C}\right)$ in darkness. Non-germinated seeds were cut opened and observed for the white viable embryo.

\section{Seed germination test}

Two samples of 3 replications of 15 seeds were incubated under ambient laboratory conditions in light/dark $\left(26 \pm 2{ }^{\circ} \mathrm{C}\right.$, diffused light through a window and white florescent light) and dark conditions. Darkness was provided by wrapping petri dishes with aluminium foil. Seeds were checked at $3 \mathrm{~d}$ intervals for germination. Radicle emergence was the criterion for germination.

\section{Embryo : seed ratio}

Fourteen seeds were incubated on moistened filter papers in petri dishes at ambient laboratory temperature (approx. $26 \pm 2{ }^{\circ} \mathrm{C}$ ) in the dark. Five seeds each were retrieved at $1 \mathrm{wk}$ intervals until the seeds started to germinate. Seeds were cut opened and the embryo and seed lengths were measured using a ruler calibrated in millimeters.

\section{Storability test}

Six samples with 3 replicates of 15 seeds were packed in polythene bags and stored in 3 temperature regimes; room temperature (approx. $26 \pm 2{ }^{\circ} \mathrm{C}$ ), household refrigerator $\left(4-8{ }^{\circ} \mathrm{C}\right)$ and freezer $\left(-2{ }^{\circ} \mathrm{C}\right)$. Seeds were stored in the above temperatures with or without moistened coir dust, resulting in 6 storage conditions. Another seed sample with 3 replicates of 15 seeds was stored in the open petri dishes as the control. Seeds were drawn after 2 months and tested for germination on moist filter papers in petri dishes under dark and light/dark conditions. The same test was conducted for the other 6 seed samples with 3 replicates of 10 seeds. One seed sample with 3 replicates of 15 seeds was stored in the open petri dishes as the control. These 6 seed samples were retrieved separately after 5 months and tested for germination as explained above. Germination test was conducted only under dark conditions (where seeds germinated well, only in the darkness).

\section{Analysis of data}

All the experiments were conducted in a completely randomized design. Data obtained from the germination tests were analyzed using a pooled t-test. Data obtained from the storage experiments were analyzed with one way ANOVA procedure and the means were separated with Duncan's multiple mean separation procedure. Data were arcsine transformed prior to analysis. Data analysis was conducted using the SAS statistical software (version 6.1). 


\section{RESULTS}

\section{Seed moisture content}

Fresh mass of the L. rotundifolia was $0.55 \pm 0.04 \mathrm{~g}$ while the dry mass was $0.37 \pm 0.02 \mathrm{~g}$. Thus, the moisture content of $L$. rotundifolia was $37 \pm 2 \%$ on a fresh mass basis.

\section{Effect of drying on seed viability}

None of the seeds air dried to $10 \%$ MC germinated, while only $23 \%$ of the seeds that were dried to $20 \% \mathrm{MC}$ germinated. All non-germinated seeds rotted and died during the germination period.

\section{Seed germination test}

Freshly collected seeds germinated only in dark conditions (58\%) (Figure1). Even in dark conditions seeds took 2 months to complete germination. Only $7 \%$ of the seeds germinated under light conditions even after 4 months. Germination under light is significantly lower than the germination in dark conditions $(\mathrm{t}=4.7, \mathrm{p}=0.04)$.

\section{Embryo : seed ratio}

Embryo : seed ratio of the fresh seeds was 0.19 . Soon after radicle emergence, the embryo : seed ratio was slightly higher $(0.24)$ than that of fresh seeds. However, this observed difference was not statistically significant $(\mathrm{t}=-1.68, \mathrm{p}=0.168)$.

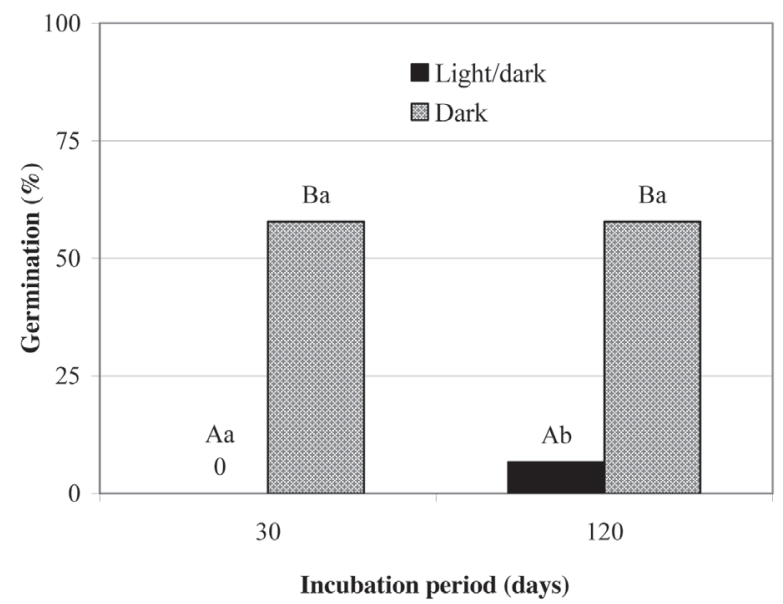

Figure 1: Germination of Livistona rotundifolia seeds in light/ dark and dark conditions at ambient laboratory temperatures $\left(\sim 26 \pm 2{ }^{\circ} \mathrm{C}\right)$. Different upper case letters depicts significant differences between different light conditions and different lower case letters depicts significant differences between 30 days incubation and 120 days incubation $(n=3)$.

\section{Storability test}

None of the seeds stored in open petri dishes germinated after 2 months or 5 months storage. They rotted and died within 2-4 weeks. Seeds kept at room temperature with coir dust germinated $57-86 \%$ (Figure 2) during the storage time [ 2 months and 5 months ( - ), respectively]. Among the seeds stored for 2 months, highest germination was shown by the seeds that were stored in polythene bags at room temperature $(-\square-)$ under dark incubation conditions $(97 \%, \mathrm{f}=6.94, \mathrm{p}<0.001)$ (Figure 2A). However, they took 4 months to reach $97 \%$ germination. Forty four percent of the seeds stored for 2 months at $4-8{ }^{\circ} \mathrm{C}$ in sealed polythene bags without coir dust $(-\downarrow)$ germinated within 4 months under laboratory temperature and light/dark conditions.
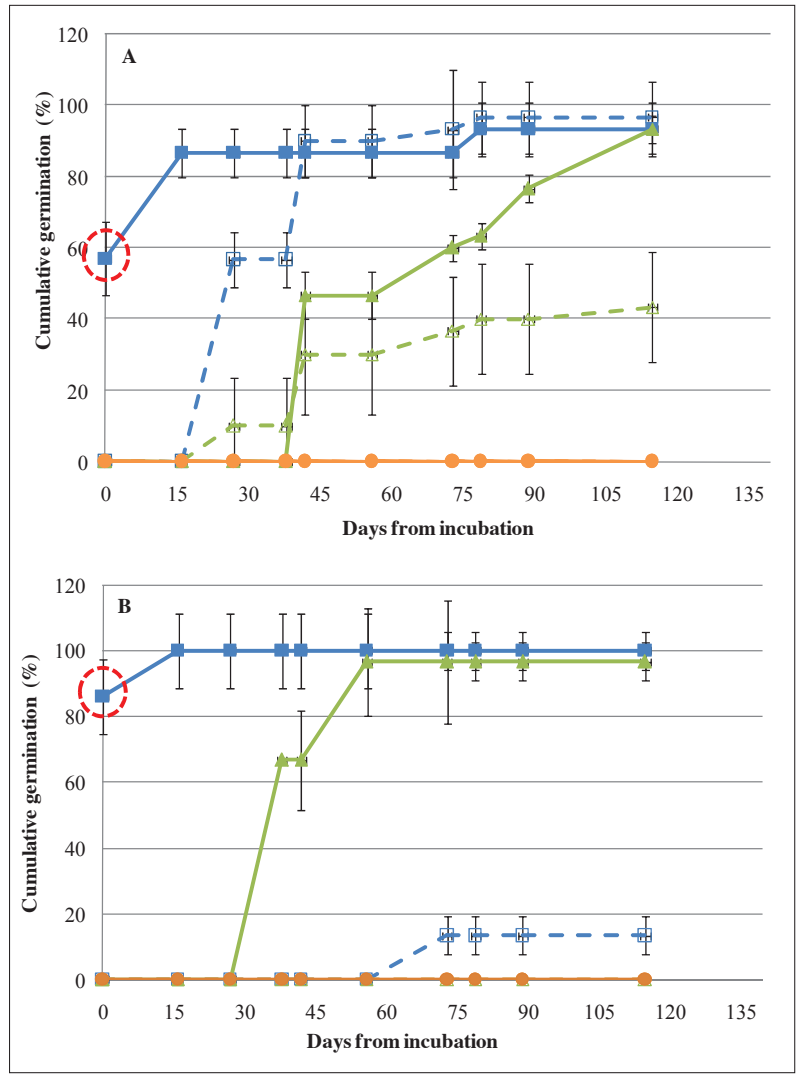

Figure 2: Germination of Livistona rotundifolia seeds in dark after 2 months (A) and 5 months (B) storage in different storage conditions [with moistened coir dust, $(-\longrightarrow)$ solid symbols with solid line; and without coir dust, (- - - ) open symbols with dashed line] at different temperatures [ambient laboratory temperature, $(\square, \square)$ squares; $4-8{ }^{\circ} \mathrm{C},(\boldsymbol{\Lambda}, \triangle)$ triangles; and $-20{ }^{\circ} \mathrm{C},(\mathbf{0}, \mathrm{O})$ circles]. Circle with dotted lines depicts the percentage seed germinated during the time of storage in the moistened coir dust. Error bars are \pm SD. $(\mathrm{n}=3)$ 
This is a significantly higher germination than that of untreated fresh seeds incubated in light/dark conditions $(6.7 \%, \mathrm{f}=12.4, \mathrm{p}=0.006)$. Among the seeds stored for 5 months, highest germination $(97 \%, \mathrm{f}=46.82$, $\mathrm{p}=0.001)$ was exhibited by seeds stored in polythene bags with coir dust at $4-8^{0} \mathrm{C}$ temperature $(\boldsymbol{-})$ in dark incubation condition (Figure 2B). However, only $13 \%$ of seeds stored in polythene bags at room temperature conditions germinated. Rest of the seeds rotted and died during incubation.

\section{DISCUSSION}

Seeds of $L$. rotundifolia have a high initial moisture content $(37 \pm 2 \%)$. Percentage moisture content of mature orthodox, intermediate and recalcitrant seeds have been recorded as $<20$ - 50, 23 - 55, 36 - 90 respecitively (Hong \& Ellis, 1996). L. rotundifolia seeds were categorized as recalcitrant due to the inability of the seeds to withstand desiccation (none of the seeds survived after desiccation to $10 \%$ seed MC). L. rotundifolia seeds may have lost the viability due to the embryo damage caused by low seed moisture content as explained by Hong and Ellis (1996). Further, L. rotundifolia seeds lost their viability during storage under sub zero temperatures (none of the L. rotundifolia seeds survived after storage at $-1{ }^{\circ} \mathrm{C}$ ). Recalcitrant seeds lose viability during storage at sub zero temperatures due to the expansion of the volume of water in the cells and due to the water crystal formation (Pammenter \& Berjak, 1999). This conclusion is in conformity with Wen and Song (2007) and Peng et al. (2011) on the L. chinensis seeds. Both these authors emphasized that mature seeds of L. chinensis are desiccation sensitive and thus, they are recalcitrant. However, Ellis et al. (2007) reported that seeds of $L$. cochinensis are orthodox. There are only a few genera recorded with recalcitrant and orthodox seed producing species (Dickie \& Pritchard, 2002). Since seeds of L. rotundifolia are recalcitrant they lose the viability when they lose moisture (Hong \& Ellis, 1996; Pammenter \& Berjak, 2000). Therefore, to maintain a long seed storage life, precautions have to be taken to prevent moisture loss during storage.

Freshly collected seeds of $L$. rotundifolia germinated only in dark conditions demonstrating that the seeds require dark conditions to germinate. However, even in dark conditions the seeds took 2 months to complete germination. Although fresh seeds have low embryo : seed ratio, it remained unchanged during the germination. Therefore, it can be concluded that $L$. rotundifolia seeds have no morphological or morphophysiological dormancy. However, most Arecaceae species produce seeds with morphological or morphophysiological dormancy (Baskin \& Baskin, 1998). Hence, this is the first confirmed record of a species producing seeds with no morphological dormancy in Arecaceae.

According to the results of the germination test L. rotundifolia seeds seem to have a slight non-deep physiological dormancy. Seeds stored for 2 months at $4-8^{0} \mathrm{C}$ in sealed polythene bags without coir dust germinated up to $71 \%$ within 4 months under laboratory temperature and light/dark conditions. This is significantly higher than the germination of untreated fresh seeds incubated in light/dark conditions. This demonstrated that wet storage at chilling conditions have increased the light sensitivity of $L$. rotundifolia seeds, suggesting that the seeds of $L$. rotundifolia have slight non-deep physiological dormancy, which can be overcome by stratification at $4-8{ }^{\circ} \mathrm{C}$ (Baskin \& Baskin, 2004).

Seeds kept at room temperature with coir dust germinated even during the storage time. Thus, it is evident that $L$. rotundifolia seeds require only a very little amount of additional water from the outside to germinate. However, none of the seeds in other storage treatments germinated during storage. Among the seeds stored for 2 months, those that were stored in polythene bags at room temperature had the highest germination under dark incubation conditions. This demonstrated that if the seeds were stored in a sealed environment to prevent moisture loss, viability could be maintained for a considerable time period even under room temperature. Among the seeds stored for 5 months, those in polythene bags with moistened coir dust in $4-8{ }^{\circ} \mathrm{C}$ temperature had the highest germination in dark incubation conditions. Thus, the best treatment for storage of $L$. rotundifolia seeds is to store at refrigerator conditions with moistened coir dust in sealed polythene bags.

Three main methods have been developed to store recalcitrant seeds such as seeds of $L$. rotundifolia, i.e. moist storage method, partial desiccation method (Chin, 1994) and anesthetic storage (Sowa \& Roos, 1991). In the moist storage method, precautions are taken to prevent the seeds from desiccation by storing seeds in a moist environment. Temperature, moisture and level of $\mathrm{O}_{2}$ have been identified as the critical factors affecting longevity of seeds during moist storage of recalcitrant seeds (King \& Roberts, 1980). Moistened sawdust, charcoal, peat and sand have been commonly used to provide the moist environment for recalcitrant seeds in storage, and in this study, moistened coir dust was used. Further, it was revealed that $4-8{ }^{\circ} \mathrm{C}$ is the best storage temperature for $L$. rotundifolia seeds. Low temperature prevents seeds from germinating during the storage period, however, sub zero temperatures cause chilling damage 
to recalcitrant seeds undesirably affecting storage life. Thus, temperatures $\sim 7{ }^{\circ} \mathrm{C}$ is recommended for storing recalcitrant seeds using the moist storage method. This is the normal temperature in a household refrigerator and is cost effective for storage of $L$. rotundifolia seeds. The polythene bag prevents moisture loss during the storage.

\section{CONCLUSION}

Livistona rotundifolia seeds require darkness to germinate. However, sensitivity to light can be slightly increased by storing seeds at low temperatures. Seeds of $L$. rotundifolia have slight non-deep physiological dormancy. According to the results obtained for moisture determination and storage tests it can be concluded that $L$. rotundifolia seeds are recalcitrant. The best storage treatment for L. rotundifolia seeds is to store them at $4-8{ }^{\circ} \mathrm{C}$ in sealed polythene bags with moistened coir dust.

\section{REFERENCES}

1. Baskin C.C. \& Baskin J.M. (1998). Seeds: Ecology, Biogeography, and Evolution of Dormancy and Germination. Academic Press, San Diego, CA, USA.

2. Baskin C.C. \& Baskin J.M. (2004). A classification system for seed dormancy. Seed Science Research 14: 1 - 16. DOI: http://dx.doi.org/10.1079/SSR2003150

3. Chin H.F. (1994). Storage of recalcitrant seeds. Seed Quality, Basic Mechanisms and Agricultural Implications (ed. A.S. Basra). Haworth Press Inc., Binghampton, NY, USA.

4. De Zoysa N. (2000). Arecaceae. A Revised Handbook to the Flora of Ceylon (eds. M.D Dassanayake \& W.D. Clayton), volume XIV, pp 33 - 93. A.A. Blakma Publishers, Leiden, The Netherlands.

5. Dickie J.B. \& Pritchard H.W. (2002). Systematic and evolutionary aspects of desiccation tolerance in seeds. Desiccation and Survival in Plants: Drying without Dying (eds. M. Black \& H.W. Pritchard), pp. 239 - 259. CAB International, Wallingford, UK.

6. Dowe J.L. (2009). A taxonomic account of Livistona R.Br. (Arecaceae). Gardens' Bulletin Singapore 60: 185 - 344.

7. Ehara H., Dowe J.L., Nagatomo R. \& Kawasaki A. (2002). Livistona chinensis var. subglobosa on Aoshima. Japan Palms 46: $62-67$.

8. Ellis R.H., Mai-Hong T., Hong T.D., Tan T.T., Xuan-Chong N.D., Hong L.Q., Ngoc-Tam B. \& Le-Tam V.T. (2007). Comparative analysis by protocol and key of seed storage behaviour of sixty Vietnamese tree species. Seed Science and Technology 35: $460-476$.

9. Hong T.D. \& Ellis R.H. (1996). A protocol to determine seed storage behaviour. IPGRI Technical Bulletin No. 1 (eds. J.M. Engels \& J. Toll). International Plant Genetic Resources Institute, Rome, Italy.

10. International Seed Testing Association (ISTA) (2008). International Rules for Seed Testing. ISTA, Zu“ richstrasse, Bassersdorf, Switzerland.

11. Jegathambigai V., Karunaratne M.D., Svinningen A. \& Mikunthan G. (2008). Biocontrol of root-knot nematode, Meloidogyne incognita damaging queen palm, Livistona rotundifolia using Trichoderma species. Agricultural Applied Biological Science 73: 681 - 700 .

12. King M.W. \& Roberts E.H. (1980). Maintenance of recalcitrant seeds in storage. Recalcitrant Crop Seeds (eds. H.F. Chin \& E.H. Roberts), pp. 53 - 89. Tropical Press, Kuala Lumpur, Malaysia.

13. Lack W.B. (2009). Martius, Book of Palms. Taschen Publisher, Hohenzollernring, Köln, Germany.

14. Pammenter N.W. \& Berjak P. (1999). A review of recalcitrant seed physiology in relation to desiccation-tolerance mechanisms. Seeds Science Research 9: 13 - 37. DOI: http://dx.doi.org/10.1017/S0960258599000033

15. Pammenter N.W. \& Berjak P. (2000). Some thoughts on the evolution and ecology of recalcitrant seeds. Plant Species Biology 15:153 - 156.

DOI: http://dx.doi.org/10.1046/j.1442-1984.2000.00035.x

16. Peng L., An-jun T., Jianiping L. \& An-cai L. (2011). Desiccation tolerance of Livistona chinensis seeds and effect of desiccation on peroxidation of their membrane lipid. Acta Horticulturae Sinica 38: 1572 - 1578.

17. Singh R.K., Srivastava R.C. \& Mukherjee T.K. (2010). Toko-Patta (Livistona jenkinsiana Griff): Adi community and conservation of culturally important endangered tree species in eastern Himalaya. Indian Journal of Traditional Knowledge 9: 231 - 241.

18. Sowa S. \& Roos E.E. (1991). Anesthetic storage of recalcitrant seed: nitrous oxide prolongs longevity of Lychee and Longan. HortScience 26: 597 - 599.

19. Svinningen A.E., Jegathambigai V. \& Mikunthan G. (2010). Nomuraea rileyi: a plausible fungi selectively controlling lepidopteron, Paraponyx stratiotata L. damaging queen palm (Livistona rotundifolia L.). Agricultural Applied Biological Science 75: $279-293$.

20. Wen B. (2009). Cytological and physiological changes related to cryotolerance in recalcitrant Livistona chinensis embryos during seed development. Protoplasma 248: 483 - 491. DOI: http://dx.doi.org/10.1007/s00709-010-0188-7

21. Wen B. \& Song S.Q. (2007). Acquisition and loss of cryotolerance in Livistona chinensis embryos during seed development. CryoLetters 28: 291 - 302. 